\title{
Simple Preparation of Ni and NiO Nanoparticles Using Raffinate Solution Originated from Spent NiMH Battery Recycling
}

\author{
Burçak Ebin $^{1}$ iD
}

Received: 8 May 2018 / Accepted: 16 July 2018 / Published online: 27 July 2018

(c) The Author(s) 2018

\begin{abstract}
Nickel $(\mathrm{Ni})$ and nickel oxide $(\mathrm{NiO})$ nanoparticles were produced by a combination of precipitation and reduction/calcination methods using the raffinate solution originated from laboratory scale spent NiMH recovery process. Ni recovery from the solution reached $99.8 \%$ by a simple precipitation step using baking soda. X-ray diffraction, FTIR spectroscopy, carbon analyzer and thermal gravimetric analysis techniques were used to characterize the precipitate. Metallic and oxide nanoparticles were obtained by hydrogen reduction and calcination under air atmosphere of the precipitate at $400{ }^{\circ} \mathrm{C}$, respectively for 30-90 min residence times. The crystal structure, crystallite size, morphology, particle size and surface area of the samples, as well as carbon residue content in the particles were detected by particle characterization methods. The results indicate that spherical Ni nanoparticles have a crystallite size about $37 \mathrm{~nm}$, and particle sizes of around $100 \mathrm{~nm}$. The agglomeration of the nanoparticles reduces by increasing residence time. NiO nanoparticles have finer crystallite and particle sizes than the metallic samples produced at the same temperature and residence times. The results show that the combination of the simple methods presented can be an alternative process for producing advanced particles from spent NiMH batteries.
\end{abstract}

Keywords Nanoparticles $\cdot$ Nickel $\cdot$ Nickel oxide $\cdot$ Nickel hydrogen carbonate $\cdot$ Spent NiMH battery $\cdot$ Hydrogen reduction . Calcination

\section{Introduction}

Nanoparticles possess unique optical, magnetic, electrical and chemical properties due to their high surface area to volume ratio, which makes them highly attractive for both the scientific and industrial community [1,2]. There is a specific interest in nickel $(\mathrm{Ni})$ and nickel oxide $(\mathrm{NiO})$ nanoparticles because of their electronic, magnetic and catalytic properties, as well as economic advantages in catalytic applications compared to noble metals [3-8].

$\mathrm{Ni}$ nanoparticles have several potential applications in magnetic devices, supercapacitors, and chemical reactions

Electronic supplementary material The online version of this article (https://doi.org/10.1007/s10904-018-0926-4) contains supplementary material, which is available to authorized users.

Burçak Ebin

burcak@chalmers.se; burcakebin@gmail.com

1 Nuclear Chemistry and Industrial Material Recycling, Department of Chemistry and Chemical Engineering, Chalmers University of Technology, Kemivägen 4,

41296 Gothenburg, Sweden as a catalyst [3, 6, 9-11]. Several methods were developed to prepare Ni nanoparticles such as thermal decomposition/ reduction $[6,10]$, wet-chemical processes $[4,9,12]$, sputtering [13] and ultrasonic spray pyrolysis [14].

$\mathrm{NiO}$ nanoparticles are a p-type semiconductor with a wide band gap between 3.6 and $4.0 \mathrm{eV} \mathrm{[15].} \mathrm{Their} \mathrm{superior}$ physico-chemical properties make them a promising candidate for advanced material applications. They can be used as electrode material for supercapacitors [16, 17], active anode material for Li-ion batteries [18], as a catalyst for chemical and electrochemical reactions [19, 20], an adsorbent for the removal of heavy metals from waste water [21, 22], and as a component in gas sensors and electronic devices [23]. The preparation of $\mathrm{NiO}$ nanoparticles was studied by microwave method [8], solvothermal process [15], precipitation and subsequent calcination [18, 19, 21], sol-gel technique [20], and a hydrothermal method with subsequent calcination [24]. In the summarized literature, pure chemicals were used as a raw material to prepare $\mathrm{Ni}$ and $\mathrm{NiO}$ nanoparticles. On the other hand, waste rich in $\mathrm{Ni}$ can be a suitable source for producing advanced Ni-based nanomaterials. 
Nickel-metal hydride (NiMH) batteries have been in the market since 1990, and this battery technology reached widespread application in a short time due to its good performance at both low and high temperatures, safety under extreme conditions, good consistency and environmental friendliness $[25,26]$. NiMH batteries are still extensively used in electric vehicles (EVs), hybrid electric vehicles (HEVs), portable power tools and modern military devices $[25,26]$. According to market review [27], the consumption of NiMH batteries will increase slightly up until 2020; their waste is a valuable secondary source not only for $\mathrm{Ni}$ and cobalt (Co), but also for rare earth elements (REE) [26, 28]. In 2006, the European Union (EU) passed the Battery Directive, one of whose aims is a higher rate of battery recycling. Member States must collect at least $45 \%$ of waste batteries in 2016 and recycle $50 \%$ by average weight of alkaline, zinc-carbon, $\mathrm{NiMH}$ and $\mathrm{Li}$-ion batteries. It also emphasizes that research and development of new, environmentally friendly and cost-effective recycling technologies should be encouraged [29].

Over the last two decades, pyrometallurgical and hydrometallurgical methods have been studied to develop a more efficient recycling process for spent NiMH batteries [30]. In the case of pyrometallurgy, battery waste is a cheap source of nickel for the steel industry [31]. The Inmetco process is one of the pyrometallurgical methods used to recycle rechargeable battery waste (NiCd, $\mathrm{NiMH}$ and Li-ion). The process uses the batteries as a secondary feedstock in addition to materials containing iron $(\mathrm{Fe})$ to reclaim the $\mathrm{Ni}, \mathrm{Co}$ and Fe to produce an iron-based alloy [32]. Müller and Friedrich [31] reported that battery waste was melted in a DC electric arc furnace to produce $\mathrm{Ni}-\mathrm{Co}$ alloys and a slag phase highly enriched with REE. In contrast, hydrometallurgical processes are based on the dissolution of the NiMH batteries in acidic solvent and the subsequent solvent-extraction to separate the REE from the $\mathrm{Ni}$ and Co leaching solution. The outcomes of the solvent extraction method are (i) organic solvent loaded with REE and other metals, and (ii) Ni rich aqueous solution, which is called raffinate solution. The obtained $\mathrm{Ni}$ rich raffinate solution requires further treatment such as precipitation or electrowinning to prepare a final $\mathrm{Ni}$ product [33, 34]. Recently, Xi et al. [35] studied the preparation of NiCo ferrite nanoparticles by sol-gel combustion using spent $\mathrm{NiMH}$ and Li-ion batteries. Although there are several studies on hydrometallurgical recycling of $\mathrm{NiMH}$ batteries, research on the preparation of final product using raffinate solution is limited.

In this research, an environmentally friendly Ni recovery process from the raffinate solution from spent NiMH batteries used in HEVs was investigated. $\mathrm{Ni}$ and $\mathrm{NiO}$ nanoparticles were produced by a combination of precipitation and $\mathrm{H}_{2}$ reduction/calcination methods using recovered $\mathrm{Ni}$ solution. The high-temperature reaction behavior of the precipitate under different atmospheres and the effects of residence time on nanoparticle properties were studied.

\section{Experimental}

Recovered Ni raffinate solution from NiMH batteries used in HEVs was chosen as starting material in the experiments. Details of the process for preparing the Ni raffinate from mixed electrodes of NiMH battery waste were published by Petranikova et al. [36]. The raffinate solution prepared by Petranikova et al. was used in the experiments. Briefly, $8 \mathrm{M}$ hydrochloric acid $(\mathrm{HCl})$ solution was added to mixed material in 1:1.96 solid to liquid ratio to dissolve the spent HEV NiMH battery electrodes. The solutions were then filtered to remove the organic components and undissolved nickel metal to obtain a clean leaching solution, which is called leachate. The leaching solutions were processed by pilot scale mixer-settler equipment. In pre-main extraction zinc and iron were separated from leachates of cathodes and mixed battery material using organic extractor (10\% Cyanex 923, 8\% tributyl phosphate-TBP, and 82\% kerosene). Aluminium and REEs are separated in main extraction stages from anode leachate and output of pre-main extraction using organic extractor (70\% Cyanex 923, 10\% TBP, and 10\% kerosene, $10 \%$ 1-Decanol) to prepare the $\mathrm{Ni}$ rich raffinate solution. Metals such as $\mathrm{Al}, \mathrm{Ce}, \mathrm{Co}, \mathrm{Fe}, \mathrm{La}, \mathrm{Mn}, \mathrm{Nd}, \mathrm{Pr}, \mathrm{Y}$ and $\mathrm{Zn}$ were loaded to organic in main extraction, while the main amount of Ni stayed in the acidic solution, known as raffinate [36]. The chemical composition of the Ni raffinate is given in Table 1.

\subsection{Precipitation}

Sodium bicarbonate $\left(\mathrm{NaHCO}_{3}\right.$, purchased from SigmaAldrich, purity $\geq 99.7$ ), also known as baking soda, was used as the precipitation agent and mixed with Milli-Q water in stoichiometric amounts to prepare $1,1.5$ and $1.96 \mathrm{M}$ aqueous solutions. $100 \mathrm{~mL}$ solutions were stirred and heated to $60{ }^{\circ} \mathrm{C}$ by a magnetic hotplate heater. Meanwhile, $10 \mathrm{~mL} \mathrm{Ni}$ raffinate solutions were placed in an ultrasonic bath (VWR,

Table 1 Elemental analysis of battery waste

\begin{tabular}{ll}
\hline Elements & $\begin{array}{l}\text { Concentration of } \\
\text { starting solution } \\
(\mathrm{g} / \mathrm{L})\end{array}$ \\
\hline $\mathrm{Ni}$ & 75.020 \\
$\mathrm{Co}$ & 0.022 \\
$\mathrm{Al}$ & 0.121 \\
$\mathrm{~K}$ & 0.507 \\
$\mathrm{La}$ & 0.073 \\
$\mathrm{Mg}$ & 0.026 \\
\hline
\end{tabular}


Ultrasonic cleaning bath, USC THD) and heated to $60{ }^{\circ} \mathrm{C}$. The sodium bicarbonate solutions were poured into the $\mathrm{Ni}$ raffinate solutions located in the ultrasonic bath at $60{ }^{\circ} \mathrm{C}$, and the final solutions were mixed with ultrasound at pouring temperature for $3 \mathrm{~h}$. Green-colored precipitates were instantly observed by mixing the solutions. The $\mathrm{pH}$ values of the suspensions were checked after the ultrasonic mixing. The suspensions were filtered to separate the precipitate from the liquid parts, and the precipitates were washed with Milli-Q water three times.

\subsection{Calcination/Reduction}

The washed precipitate was used to produce $\mathrm{Ni}$ and $\mathrm{NiO}$ nanoparticles. In the experiments, the weight of the washed precipitate was $1 \mathrm{~g}$; it was put into a ceramic combustion boat. The combustion boat was placed inside a horizontal quartz tube located in an electrically heated tube furnace with a temperature control of $\pm 1{ }^{\circ} \mathrm{C}$ at the reaction temperature. The calcination and reduction processes were performed at $400{ }^{\circ} \mathrm{C}$ for 30,60 and 90 min residence times under constant gas flow rates.

Air with a gas flow rate of $1.0 \mathrm{~L} / \mathrm{min}$ was used to produce $\mathrm{NiO}$ nanoparticles. The combustion boats were loaded into the furnace under air atmosphere at $400{ }^{\circ} \mathrm{C}$. After the desired calcination times, the combustion boats were removed from the furnace at the reaction temperature to room temperature under air atmosphere.

A 5\% $\mathrm{H}_{2}-\mathrm{N}_{2}$ mixture (Air Liquide, Mixture Crystal) with a gas flow rate of $1.0 \mathrm{~L} / \mathrm{min}$ was used to produce Ni nanoparticles. The reaction zone was purged by a $1.0 \mathrm{~L} / \mathrm{min}_{2(\mathrm{~g})}$ flow for $1 \mathrm{~min}$ before and after the reaction for safety reasons. The combustion boats were loaded into the furnace under $\mathrm{N}_{2(\mathrm{~g})}$ atmosphere at $400{ }^{\circ} \mathrm{C}$ reaction temperature, and the gas was then switched to a $5 \% \mathrm{H}_{2}-\mathrm{N}_{2}$ mixture. After the desired hydrogen reduction times, the combustion boats were removed from the furnace at the reaction temperature to room temperature under $\mathrm{N}_{2(\mathrm{~g})}$ atmosphere.

\subsection{Characterization}

The nickel content in the solutions after precipitation was analyzed by inductively coupled plasma optical emission spectrometry (ICP-OES, ICAP 6500, Thermo Fisher) to calculate the nickel recovery amount. Fourier transform infrared spectroscopy (FTIR- Perkin Elmer Spectrum Two) was used to detect the composition of the washed precipitate. Thermal gravimetric analyses (TA Instruments, TGAQ500) were performed at temperatures ranging from 25 to $1000{ }^{\circ} \mathrm{C}$ under air, nitrogen and $5 \% \mathrm{H}_{2}-\mathrm{N}_{2}$ gas mixture atmospheres separately.

X-ray diffraction (XRD, Bruker D8 Advance) using $\mathrm{Cu} \mathrm{K} \alpha$ radiation was used to examine the crystalline compounds, crystalline structure and crystallite size of the samples. A carbon analyzer (LECO Carbon/Sulfur Analyzer CS744) was used to determine the carbon content of the washed precipitate, $\mathrm{Ni}$ and $\mathrm{NiO}$ nanoparticles. The particle size and morphology of the samples were investigated using a field emission scanning electron microscope (FEI, Quanta 200 FEG ESEM). The analyses of particle size and size distribution of the obtained $\mathrm{Ni}$ and $\mathrm{NiO}$ nanoparticles were performed using a BI-90 particle sizer instrument from Brookhaven Instruments Corporation. The surface area of the samples were measured by BET analysis (Micromeritics ASAP 2020 Surface Area and Porosity Analyzer). BET surface area is also related to average particle size where the average particle size was calculated using the following equation;

$\mathrm{S}_{\mathrm{BET}}=6000 / \rho \mathrm{d}_{\mathrm{BET}}$

where $S_{\mathrm{BET}}$ is the BET surface area $\left(\mathrm{m}^{2} / \mathrm{g}\right), \rho$ is the density of the sample $\left(\mathrm{g} / \mathrm{cm}^{3}\right)$ and $\mathrm{d}_{\mathrm{BET}}$ is the calculated average particle size (nm) [37].

\section{Results and Discussion}

The elemental analysis of the Ni raffinate solution (starting solution) is given in Table 1 . The solution contains a high amount of $\mathrm{Ni}$ and negligible amounts of other metals (Co, $\mathrm{Al}, \mathrm{K}, \mathrm{La}$, and $\mathrm{Mg}$ ) coming from the spent NiMH battery recycling process. Table 2 shows the Ni precipitation amount depending on $\mathrm{NaHCO}_{3}$ concentration. The highest concentration used was $1.96 \mathrm{M}$ as it is the solubility limit of $\mathrm{NaHCO}_{3}$ in water at $60{ }^{\circ} \mathrm{C}$. Ni precipitation reached $99.8 \%$ using 1.5 and $1.96 \mathrm{M} \mathrm{NaHCO}_{3}$ solutions, while the final $\mathrm{pH}$ values of the mixtures were observed as 7.6 and 8.0 respectively. The detailed elemental analyses after precipitation are given in the supplementary document.

The $1.5 \mathrm{M}$ concentrated solution was decided as the optimum nickel precipitation condition due to the high recovery amount while consuming less baking soda. The characterization studies were conducted by analyzing this precipitate. The XRD patterns of the precipitate before and after washing are shown in Fig. 1. Before washing, $\mathrm{NaCl}$ peaks are

Table $2 \mathrm{pH}$ values of the solutions and Ni precipitation amount from the waste solution by sol-gel process mixed in ultrasonic bath for $3 \mathrm{~h}$ at $60{ }^{\circ} \mathrm{C}$

\begin{tabular}{llll}
\hline Sample & $\begin{array}{l}\text { Concentration of } \\
\mathrm{NaHCO}_{3} \text { solution (M) }\end{array}$ & $\begin{array}{l}\mathrm{pH} \text { of the } \\
\text { solution }\end{array}$ & $\begin{array}{l}\text { Ni precipita- } \\
\text { tion amount, } \\
\%\end{array}$ \\
\hline 1 & 1.00 & 6.3 & 92.1 \\
2 & 1.50 & 7.6 & 99.8 \\
3 & 1.96 & 8.0 & 99.8 \\
\hline
\end{tabular}


Fig. 1 XRD patterns of $(a)$ precipitated sample and $(b)$ after washing

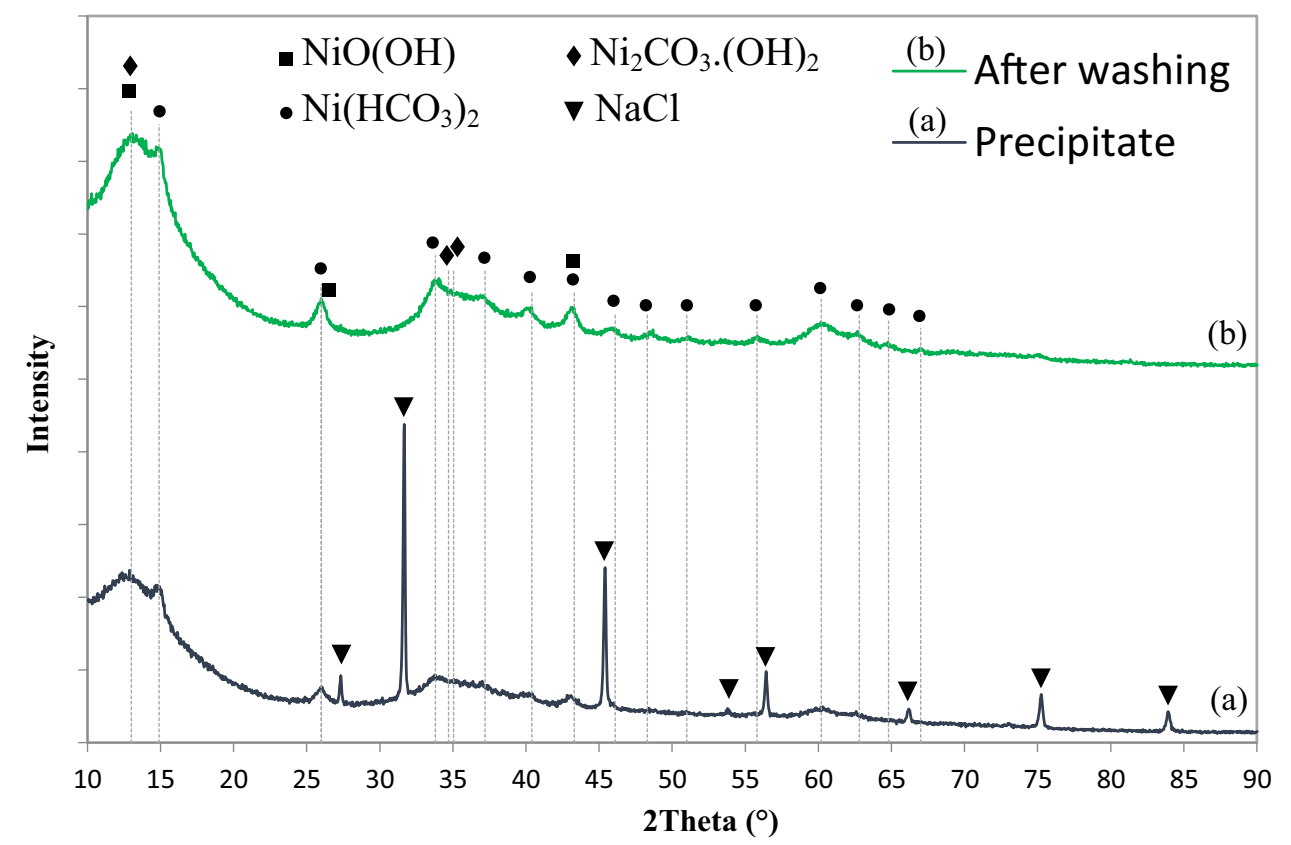

dominant in the structure denoting the existence of a $\mathrm{NaCl}$ salt content in the precipitate. $\mathrm{Cl}^{-}$anions in the raffinate solution reacted with $\mathrm{Na}^{+}$cations in the precipitating agent to form salt. After washing, the salt was removed and the $\mathrm{Ni}$ salt peaks became clear. Although nickel(II) hydrogen carbonate $\left(\mathrm{Ni}\left(\mathrm{HCO}_{3}\right)_{2}\right)$ is the dominant structure in the washed sample, the peaks of nickel oxide hydroxide $(\mathrm{NiO}(\mathrm{OH}))$ and nickel carbonate hydroxide $\left(\mathrm{Ni}_{2} \mathrm{CO}_{3}(\mathrm{OH})_{2}\right)$ [JCPDS 35-0501] can be faintly observed in the XRD pattern.
The carbon content of the washed precipitate is measured as $4.39 \mathrm{wt} \%$. In contrast, the carbon contents of $\mathrm{Ni}\left(\mathrm{HCO}_{3}\right)_{2}$ and $\mathrm{Ni}_{2} \mathrm{CO}_{3}(\mathrm{OH})_{2}$ are nearly 13.2 and $5.68 \mathrm{wt} \%$, respectively. The XRD patterns and carbon analysis result clearly show that washed precipitate contains three structure, $\mathrm{Ni}\left(\mathrm{HCO}_{3}\right)_{2}, \mathrm{Ni}_{2} \mathrm{CO}_{3}(\mathrm{OH})_{2}$, and $\mathrm{NiO}(\mathrm{OH})$.

Figure 2 shows the FTIR spectrum of the washed precipitate. The broad absorption band at around $3450 \mathrm{~cm}^{-1}$ can be attributed to $\mathrm{O}-\mathrm{H}$ stretching vibrations. The band at
Fig. 2 FTIR spectrum of the washed precipitate

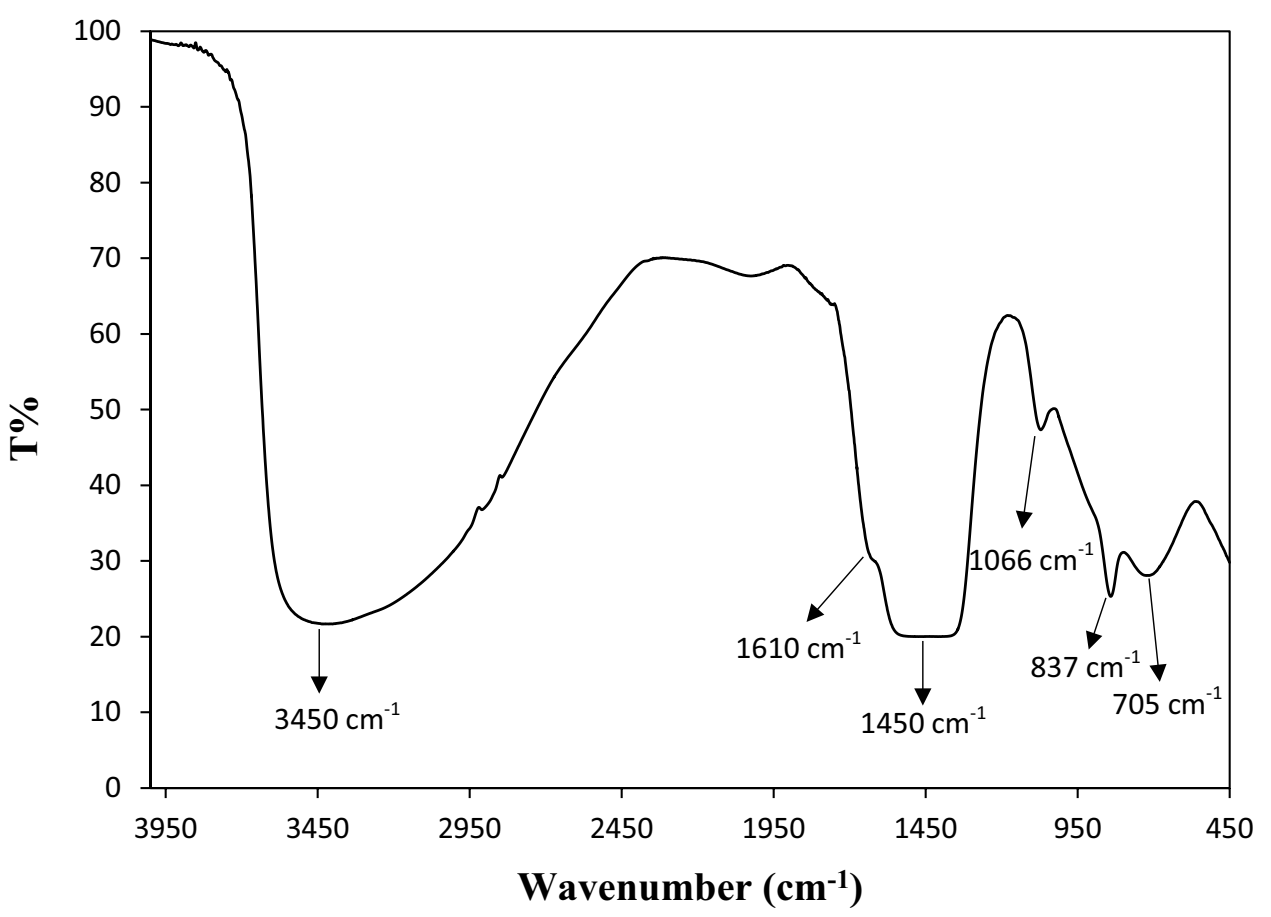


around $1610 \mathrm{~cm}^{-1}$ is probably due to the $\mathrm{H}-\mathrm{O}-\mathrm{H}$ bending vibration of adsorbed water. The three bands at 1450, 1066, and $837 \mathrm{~cm}^{-1}$ are the characteristics of carbonate ions. The band at $705 \mathrm{~cm}^{-1}$ can be associated with $\mathrm{Ni}-\mathrm{O}$ stretching vibration and $\mathrm{Ni}-\mathrm{O}-\mathrm{H}$ bending vibrations.

TGA curves of the washed precipitate under air, $\mathrm{N}_{2(\mathrm{~g})}$ and $5 \% \mathrm{H}_{2}-\mathrm{N}_{2}$ gas mixture atmospheres from room temperature to $1000{ }^{\circ} \mathrm{C}$ are given in Fig. 3. The sample has nearly the same thermal behavior under air and $\mathrm{N}_{2(\mathrm{~g})}$ atmospheres. Two different slopes were observed from room temperature to $250{ }^{\circ} \mathrm{C}$. The first slope to $150{ }^{\circ} \mathrm{C}$ concerns the evaporation of the adsorbed water, which shows an almost $10 \%$ weight loss. At the temperatures between 150 and $250{ }^{\circ} \mathrm{C}$, the additional $4 \%$ weight loss is probably related to decomposition

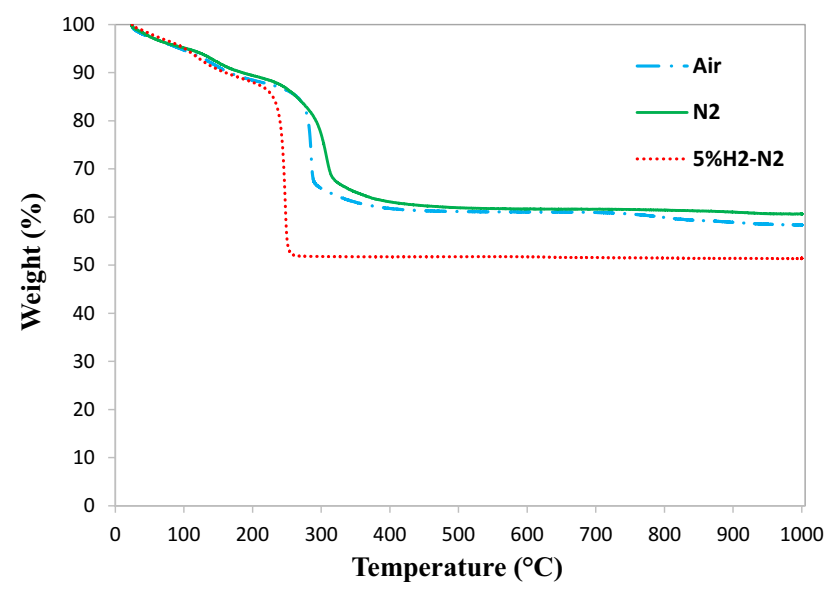

Fig. 3 TGA curves of the washed precipitate obtained under air, nitrogen and $5 \% \mathrm{H}_{2}-\mathrm{N}_{2}$ atmospheres of hydrates. The $24 \%$ weight loss between 250 and $400{ }^{\circ} \mathrm{C}$ represents the decomposition of nickel carbonates to NiO. Under air atmosphere, a slight decrease in weight at around $700{ }^{\circ} \mathrm{C}$ indicates the combustion of carbon residue. Under a $5 \% \mathrm{H}_{2}-\mathrm{N}_{2}$ gas mixture, the weight loss in the first two steps is almost the same, but the reaction plateau ended at lower temperatures compared to other atmospheres. The hydrogen reduction reaction of the sample to metallic $\mathrm{Ni}$ started at 220 and ended at $260{ }^{\circ} \mathrm{C}$, showing a weight loss of almost $35 \%$.

\subsection{Ni Nanoparticles}

$\mathrm{Ni}$ nanoparticles were produced by hydrogen reduction of the washed precipitate at $400{ }^{\circ} \mathrm{C}$ at residence times of 30-90 mim. Figure 4 shows the XRD patterns of the obtained $\mathrm{Ni}$ nanoparticles. The diffraction peaks of the Ni particles are indexed to face centered cubic (FCC) structure with Fm-3m space group, which are consistent with PDF Card No: 04-010-6148. The crystallite sizes of the particles were calculated by Scherrer equation using (111), (200) and (220) peaks in the XRD patterns. Instrumental broadening was taken into account to obtain accurate crystallite sizes in the calculation. The crystallite sizes of the Ni nanoparticles are 37,37 and $42 \mathrm{~nm}$ by increasing residence time from 30 to 60 and $90 \mathrm{~min}$, respectively.

The carbon content of the washed precipitate and $\mathrm{Ni}$ nanoparticles are given in Table 3. The carbon content of the particles fell initially and then became almost stable by increasing residence time from 30 to 60 and $90 \mathrm{~min}$. Figure 5 shows the SEM images of the Ni nanoparticles. All samples exhibit nearly spherical morphology, and the average
Fig. 4 XRD patterns of Ni particles prepared at $400{ }^{\circ} \mathrm{C}$ using $5 \% \mathrm{H}_{2}-\mathrm{N}_{2}$ gas mixture with flow rate of $1 \mathrm{~L} / \mathrm{min}$ for $($ a) $30 \mathrm{~min}$, (b) $60 \mathrm{~min}$ and (c) $90 \mathrm{~min}$

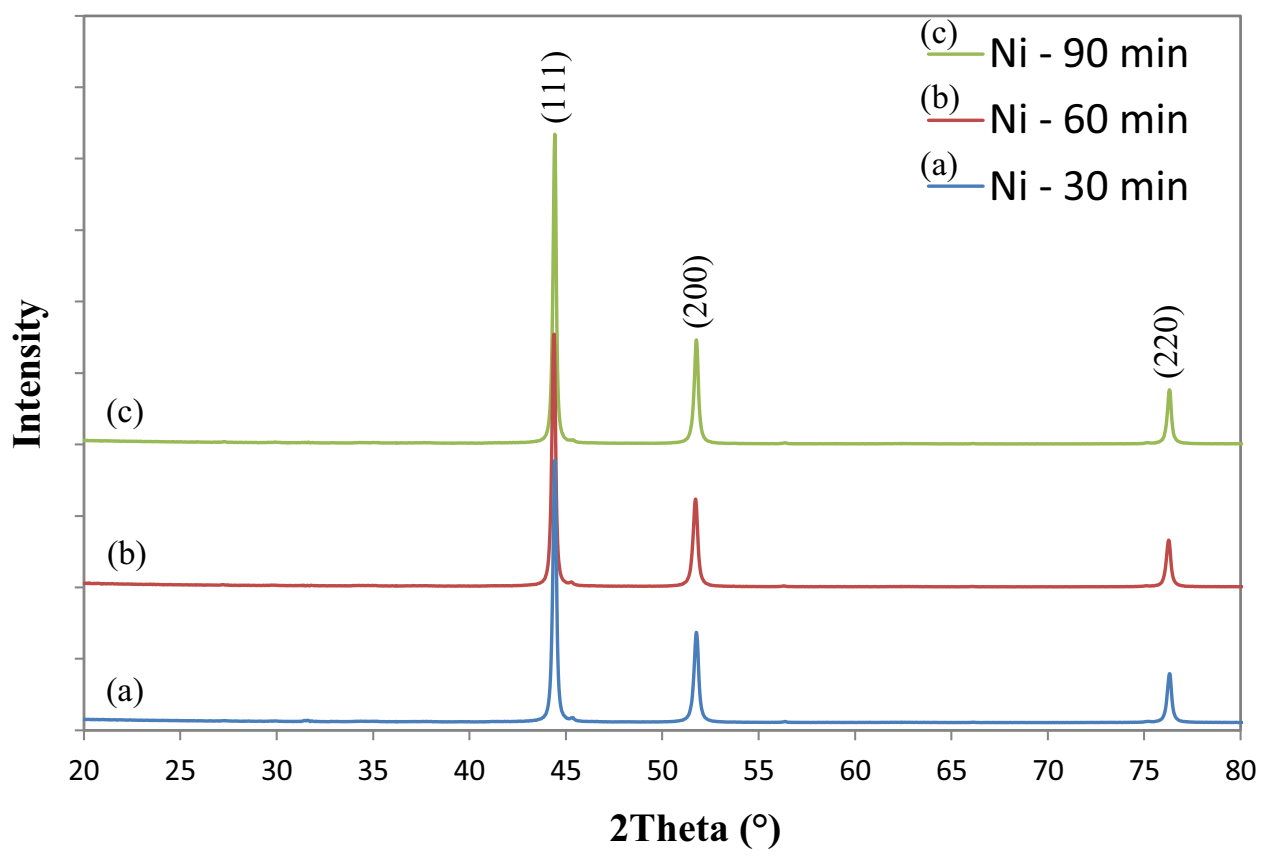


Table 3 Carbon content of Ni nanoparticles produced at $400{ }^{\circ} \mathrm{C}$

\begin{tabular}{lc}
\hline Reduction time & Carbon amount, wt\% \\
\hline Starting material & $4.39 \pm 0.0448$ \\
$30 \mathrm{~min}$ & $0.762 \pm 0.0115$ \\
$60 \mathrm{~min}$ & $0.703 \pm 0.0626$ \\
$90 \mathrm{~min}$ & $0.701 \pm 0.0128$ \\
\hline
\end{tabular}

Fig. 5 SEM images Ni particles prepared at $400{ }^{\circ} \mathrm{C}$ using $5 \% \mathrm{H}_{2}-$ $\mathrm{N}_{2}$ gas mixture with flow rate of $1 \mathrm{~L} / \mathrm{min}$ for a $30 \mathrm{~min}, \times 20 \mathrm{~K}, \mathbf{b}$ $30 \mathrm{~min}, \times 60 \mathrm{~K}, \mathrm{c} 60 \mathrm{~min}, \times 20 \mathrm{~K}$, d $60 \mathrm{~min}, \times 60 \mathrm{~K}$, e $90 \mathrm{~min}$, $\times 20 \mathrm{~K}$ and $\mathbf{f} 90 \mathrm{~min}, \times 60 \mathrm{~K}$ particle size from the SEM images varies between 100 and $130 \mathrm{~nm}$.

Table 4 presents the average particle size and size distribution of the Ni nanoparticles measured by dynamic light scattering. The measured particle sizes are bigger than the observed results due to the agglomeration of the samples. The liberation of the individual nanoparticles from agglomerates is limited in the Ni samples. Furthermore, the measured particle size reduced by increasing residence time. Probably, carbon residue caused agglomeration of the finer particles, and even though removal of the carbon content
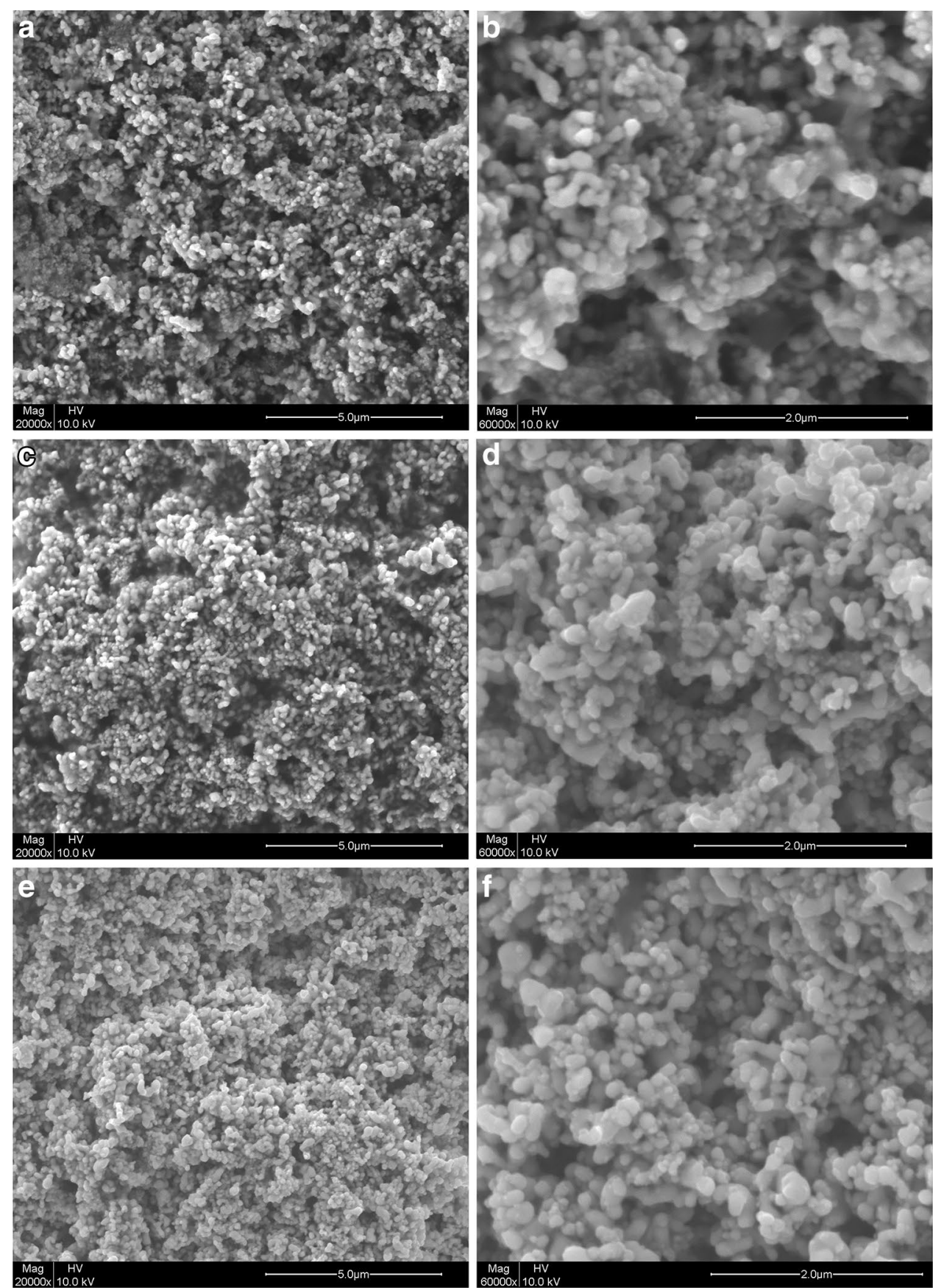
Table 4 Size distribution of Ni nanoparticles produced at $400{ }^{\circ} \mathrm{C}$

\begin{tabular}{lllllll}
\hline $\begin{array}{l}\text { Reduction } \\
\text { time }(\mathrm{min})\end{array}$ & $\begin{array}{l}\text { Average parti- } \\
\text { cle size }(\mathrm{nm})\end{array}$ & \multicolumn{2}{l}{ Cumulative undersize $(\mathrm{nm})$} \\
\cline { 3 - 7 } & & $10 \%$ below & $25 \%$ below & $50 \%$ below & $75 \%$ below & $90 \%$ below \\
\hline 30 & $874 \pm 11$ & 304 & 453 & 704 & 1096 & 1634 \\
60 & $765 \pm 8$ & 301 & 421 & 613 & 892 & 1250 \\
90 & $534 \pm 13$ & 285 & 368 & 489 & 649 & 837 \\
\hline
\end{tabular}

Table 5 BET surface area of Ni nanoparticles produced at $400^{\circ} \mathrm{C}$

\begin{tabular}{lll}
\hline Reduction time $(\mathrm{min})$ & BET surface area $\left(\mathrm{m}^{2} / \mathrm{g}\right)$ & $\begin{array}{l}\text { Calculated } \\
\text { particle size } \\
(\mathrm{nm})\end{array}$ \\
\hline 30 & $5.93 \pm 0.05$ & 114 \\
60 & $5.76 \pm 0.06$ & 117 \\
90 & $5.64 \pm 0.05$ & 119 \\
\hline
\end{tabular}

was too low over time, it decreased the degree of agglomeration. The BET surface areas and calculated particle sizes of the Ni particles are given in Table 5. The particle surface areas are reduced slightly by increasing residence time, which is clearly an effective factor for inducing the particle growth. The particle sizes calculated using surface area are nearly the same as the results observed on the SEM images.

\subsection{NiO Particles}

$\mathrm{NiO}$ nanoparticles were produced by calcination of the washed precipitate at $400{ }^{\circ} \mathrm{C}$ for 30-90 min residence times using $1 \mathrm{~L} / \mathrm{min}$ air flow. Figure 6 shows the XRD patterns of the NiO nanoparticles. The diffraction peaks of the $\mathrm{NiO}$ particles correspond to face centered cubic (FCC) structure with Fm-3m space group which are consistent with PDF Card No: 04-001-9373. The crystallite sizes of the particles were calculated by Scherrer equation using (111), (200) and (220) peaks in the XRD patterns. Instrumental broadening was taken into account to obtain accurate crystallite sizes in the calculation. The crystallite sizes of the $\mathrm{NiO}$ nanoparticles were detected as 9,10 and $12 \mathrm{~nm}$ by increasing residence time from 30 to 60 and $90 \mathrm{~min}$, respectively.

The carbon content of the starting material (washed precipitate) and $\mathrm{NiO}$ nanoparticles are given in Table 6 . Initially, the carbon content of the particles first sharply decreased sharply due to a decomposition reaction to $\mathrm{NiO}$, and then became almost stable by changing the residence time. Figure 7 shows the SEM images of the NiO

Table 6 Carbon content of $\mathrm{NiO}$ nanoparticles produced at $400{ }^{\circ} \mathrm{C}$

\begin{tabular}{lc}
\hline Calcination time & Carbon amount, wt $\%$ \\
\hline Starting material & $4.39 \pm 0.0448$ \\
$30 \mathrm{~min}$ & $0.550 \pm 0.0067$ \\
$60 \mathrm{~min}$ & $0.582 \pm 0.0177$ \\
$90 \mathrm{~min}$ & $0.552 \pm 0.0026$ \\
\hline
\end{tabular}

Fig. 6 XRD patterns of $\mathrm{NiO}$ particles prepared at $400{ }^{\circ} \mathrm{C}$ using air with flow rate of $1 \mathrm{~L} /$ min for (a) $30 \mathrm{~min},(b) 60 \mathrm{~min}$ and $(c) 90 \mathrm{~min}$

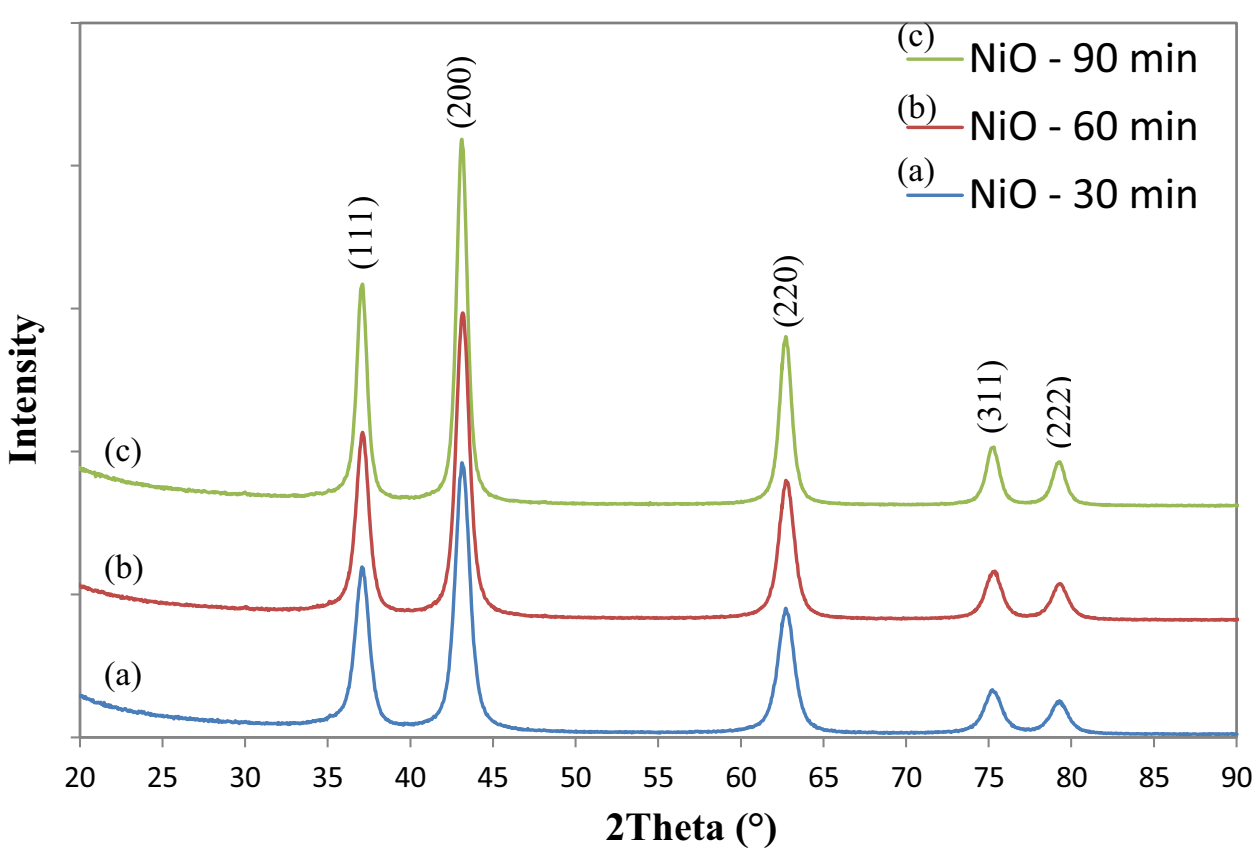


Fig. 7 SEM images $\mathrm{NiO}$ particles prepared at $400{ }^{\circ} \mathrm{C}$ using air with flow rate of $1 \mathrm{~L} / \mathrm{min}$ for a $30 \mathrm{~min}, \times 20 \mathrm{~K}, \mathbf{b} 30 \mathrm{~min}$, $\times 60 \mathrm{~K}, \mathrm{c} 60 \mathrm{~min}, \times 20 \mathrm{~K}, \mathbf{d}$ $60 \mathrm{~min}, \times 60 \mathrm{~K}, \mathrm{e} 90 \mathrm{~min}, \times 20 \mathrm{~K}$ and $\mathbf{f} 90 \mathrm{~min}, \times 60 \mathrm{~K}$
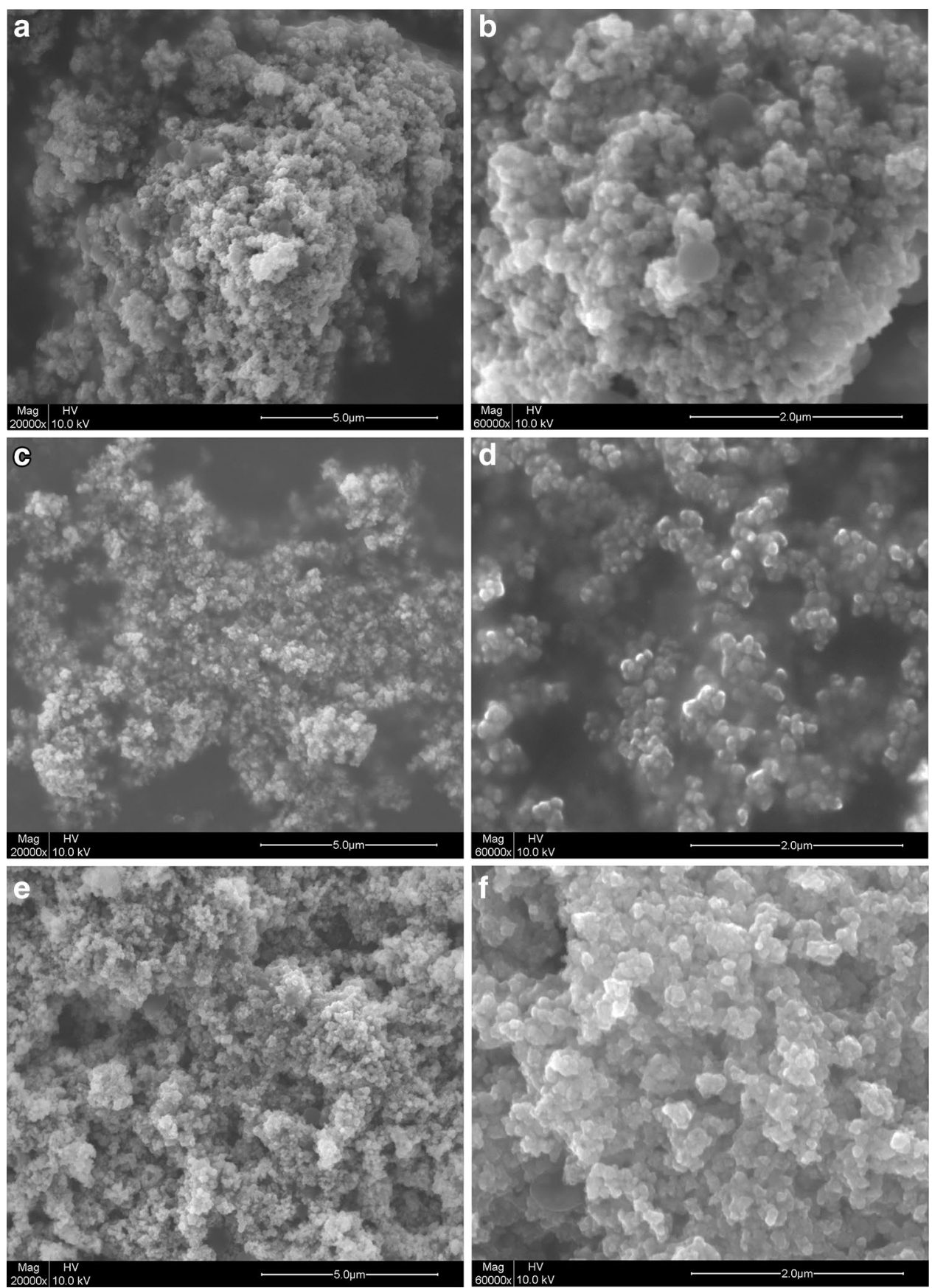

nanoparticles. All samples exhibit nearly spherical morphology, and the average particle size from the SEM images increases slightly from 75 to 83 and $98 \mathrm{~nm}$ depending on the increased residence time.

The average $\mathrm{NiO}$ particle size and size distribution measured by dynamic light scattering are given in Table 7. The measured particle sizes were coarser than the observed results due to agglomeration of the samples. The extended calcination residence time provided a suitable environment for particle growth and agglomeration, and thus the measured $\mathrm{NiO}$ particle size increased over time. Table 8 presents the BET surface areas and calculated sizes of the NiO particles. The particle surface areas decreased from $68.81 \pm 0.44$ to $50.36 \pm 0.33 \mathrm{~m}^{2} / \mathrm{g}$ by increasing residence time, a greater reduction percentage compared to Ni nanoparticles. Particle sizes calculated using surface areas are between 13 and $18 \mathrm{~nm}$. For Ni and $\mathrm{NiO}$ particles of the same size, residence time should be more active for metallic Ni particle growth since $\mathrm{NiO}$ particles tend be more stable [38]. It is clear that nanostructures with smaller particle sizes are more sensitive to growth with residence time. 
Table 7 Size distribution of $\mathrm{NiO}$ nanoparticles produced at $400^{\circ} \mathrm{C}$

\begin{tabular}{|c|c|c|c|c|c|c|}
\hline \multirow{2}{*}{$\begin{array}{l}\text { Calcination } \\
\text { time (min) }\end{array}$} & \multirow{2}{*}{$\begin{array}{l}\text { Average parti- } \\
\text { cle size }(\mathrm{nm})\end{array}$} & \multicolumn{5}{|c|}{ Cumulative undersize (nm) } \\
\hline & & $10 \%$ below & $25 \%$ below & $50 \%$ below & $75 \%$ below & $90 \%$ below \\
\hline 30 & $481 \pm 3$ & 266 & 339 & 444 & 581 & 741 \\
\hline 60 & $560 \pm 6$ & 261 & 353 & 495 & 693 & 938 \\
\hline 90 & $656 \pm 20$ & 257 & 368 & 550 & 820 & 1177 \\
\hline
\end{tabular}

Table 8 BET surface area of $\mathrm{NiO}$ nanoparticles produced at $400^{\circ} \mathrm{C}$

\begin{tabular}{lll}
\hline $\begin{array}{l}\text { Calcination time } \\
(\mathrm{min})\end{array}$ & BET surface area $\left(\mathrm{m}^{2} / \mathrm{g}\right)$ & $\begin{array}{l}\text { Calculated } \\
\text { particle size } \\
(\mathrm{nm})\end{array}$ \\
\hline 30 & $68.81 \pm 0.44$ & 13 \\
60 & $63.83 \pm 0.43$ & 14 \\
90 & $50.36 \pm 0.33$ & 18 \\
\hline
\end{tabular}

\section{Conclusion}

$\mathrm{Ni}$ and $\mathrm{NiO}$ nanoparticles were successfully produced by a combination of precipitation and reduction/calcination methods using raffinate solution obtained by the recovery of spent NiMH batteries. The advantage of the method is in using the baking soda as a precipitation agent instead of harmful chemicals to recover the Ni from the solution, which makes it more environmentally sound process. Furthermore, the precipitated nickel carbonate-based compound can decompose to form $\mathrm{NiO}$ under air at low temperatures as well as effectively reducing to pure metallic $\mathrm{Ni}$ under a $5 \% \mathrm{H}_{2}-\mathrm{N}_{2}$ atmosphere at $400{ }^{\circ} \mathrm{C}$. In the method described, $99.8 \%$ of the $\mathrm{Ni}$ in the recovered solution was reclaimed as advance particulate material. The carbon residue on the metallic samples reduced the liberation of the $\mathrm{Ni}$ nanoparticles at sizes around $100 \mathrm{~nm}$ and caused agglomeration. On the other hand, $\mathrm{NiO}$ nanoparticles were obtained in finer sizes and residence time had a strong impact on particle growth for the smaller nanoparticles. The combination of simple, environmentally friendly and inexpensive methods of producing advanced particles from waste can be an innovative path to achieving considerable progress in the recycling concept.

Acknowledgements This research was supported by Åforsk Foundation (Grant No.: 17-539).

Open Access This article is distributed under the terms of the Creative Commons Attribution 4.0 International License (http://creativeco mmons.org/licenses/by/4.0/), which permits unrestricted use, distribution, and reproduction in any medium, provided you give appropriate credit to the original author(s) and the source, provide a link to the Creative Commons license, and indicate if changes were made.

\section{References}

1. G. Palasantzas, S.A. Koch, T. Vsytavel, J. Th., M. De Hosson, Opportunities from the nanoworld: gas phase nanoparticles. J. Alloy. Compd. 449, 237-241 (2008)

2. W.J. Stark, P.R. Stoessel, W. Wohlleben, A. Hafner, Industrial applications of nanoparticles. Chem. Soc. Rev. 44, 5793-5805 (2015)

3. S.-H. Park, H.-S. Kim, Flash light sintering of nickel nanoparticles for printed electronics. Thin Solid Films 550, 575-581 (2014)

4. Z. Jiang, X.J. Xie, D. Jiang, X. Wei, M. Chen, Modifiers-assisted formation of nickel nanoparticles and their catalytic application to p-nitrophenol reduction. Cryst. Eng. Comm. 15, 560-569 (2013)

5. R.G. Chaudhary, J.A. Tanna, N.V. Gandhare, A.R. Rai, H.D. Juneja, Synthesis of nickel nanoparticles: microscopic investigation, an efficient catalyst and effective antibacterial activity. Adv. Mater. Lett. 6/11, 990-998 (2015)

6. X. He, W. Zhong, C.-T. Au, Y. Du, Size dependence of the magnetic properties of Ni nanoparticles prepared by thermal decomposition method. Nanoscale Res. Lett. 8, 446-455 (2013)

7. D. Nikolić, M. Panjan, G.R. Blake, M. Tadić, Annealing-dependent structural and magnetic properties of nickel oxide $(\mathrm{NiO})$ nanoparticles in a silica matrix. J. Eur. Ceram. Soc. 35, 3843-3852 (2015)

8. A.L. Gajengi, T. Sasaki, B.M. Bhanage, NiO nanoparticles catalyzed three component coupling reaction of aldehyde, amine and terminal alkynes. Catal. Commun. 72, 174-179 (2015)

9. X. Wu, W. Xing, L. Zhang, S. Zhuo, J. Zhuo, G. Wang, S. Qiao, Nickel nanoparticles prepared by hydrazine hydrate reduction and their application in supercapacitor. Powder Technol. 224, 162-167 (2012)

10. H. Inokawa, T. Ichikawa, H. Miyaoka, Catalysis of nickel nanoparticles with high thermal stability for ammonia decomposition. Appl. Catal. A 491, 184-188 (2015)

11. M. Gong, D.-Y. Wang, C.-C. Chen, B.-J. Hwang, H. Dai, A mini review on nickel-based electrocatalysts for alkaline hydrogen evolution reaction. Nano Res. 9, 28-46 (2016)

12. C.J. Pandian, R. Palanivel, S. Dhananasekaran, Green synthesis of nickel nanoparticles using Ocimum sanctum and their application in dye and pollutant adsorption. Chin. J. Chem. Eng. 23, 1307-1315 (2015)

13. M. Maicas, M. Sanz, H. Cui, C. Aroca, P. Sánchez, Magnetic properties and morphology of Ni nanoparticles synthesized in gas phase. J. Magn. Magn. Mater. 322, 3485-3489 (2010)

14. B. Ebin, S. Gurmen, Synthesis and characterization of nickel particles by hydrogen reduction assisted ultrasonic spray pyrolysis (USP-HR) method. KONA Powder Particle J. 29, 134-140 (2011)

15. K. Anandan, V. Rajendran, Morphological and size effects of $\mathrm{NiO}$ nanoparticles via solvothermal process and their optical properties. Mater. Sci. Semicond. Process. 14/1, 43-47 (2011)

16. W. Yu, X. Jiang, S. Ding, B.Q. Li, Preparation and electrochemical characteristics of porous holow spheres of $\mathrm{NiO}$ nanosheets as electrodes of supercapacitors. J. Power Sources 256, 440-448 (2014) 
17. A. Barani, M. Aghazadeh, M.R. Ganjali, B. Sabour, A.-A.M. Barmi, S. Dalvand, Nanostructured nickel oxide ultrafine nanoparticles: synthesis, characterization, and supercapacitive behavior. Mater. Sci. Semicond. Process. 23, 85-92 (2014)

18. G. Zhang, Y. Chen, B. Qu, L. Hu, L. Mei, D. Lei, Q. Li, L. Chen, Q. Li, T. Wang, Synthesis of mesoporous NiO nanospheres as anode materials for lithium ion batteries. Electrochemica Acta 80, 140-147 (2012)

19. M.A. Nasseri, F. Kamali, B. Zakerinasab, Catalytic activity of reusable nickel oxide nanoparticles in the synthesis of spirooxindoles. RSC Adv. 5, 26517-26520 (2015)

20. A.S. Danial, M.M. Saleh, S.A. Salih, M.I. Awad, On the synthesis of nickel oxide nanoparticles by sol-gel technique and its electrocatalytic oxidation of glucose. J. Power Sources 293, 101-108 (2015)

21. M.A. Behnajady, S. Bimeghdar, Synthesis of mesoporous NiO nanoparticles and their application in the adsorption of $\mathrm{Cr}(\mathrm{VI})$. Chem. Eng. J. 239, 105-113 (2014)

22. T. Sheela, Y.A. Nayaka, Kinetics and thermodynamics of cadmium and lead ions adsorption on $\mathrm{NiO}$ nanoparticles. Chem. Eng. J. 191, 123-131 (2012)

23. S. Pilban Jahromi, N.M. Huang, M.R. Muhamad, H.N. Lim, Green gelatine-assisted sol-gel synthesis of ultrasmall nickel oxide nanoparticles. Ceram. Int. 39, 3909-3914 (2013)

24. Y.-Z. Zheng, H.-Y. Ding, M.-I. Zhang, Preparation and electrochemical properties of nickel oxide as a supercapacitor electrode material. Mater. Res. Bull. 44/2, 403-407 (2009)

25. C.C. Yang, C.C. Wang, M.M. Li, Q. Jiang, A start of the renaissance for nickel metal hydride batteries: a hydrogen storage alloy series with an ultra-long cycle life. J. Mater. Chem. A 5, 1145$1152(2017)$

26. S.-L. Lin, K.-L. Huang, I.-C. Wang, I.-C. Chou, Y.-M. Kuo, C.-H. Hung, Characterization of spent nickel-metal hydride batteries and a preliminary economic evaluation of the recovery processes. J. Air Waste Manage. 66/3, 296-306 (2016)

27. C. Pillot, Avicenne Market Review "Battery Market Development for Consumer Electronics, Automotive, and Industrial: Materials Requirements \& Trends", https://www.rechargebatteries.org/wpcontent/uploads/2015/01/Avicenne-market-review-Nive-2014.pdf. Accessed 10 June 2018
28. M.S. Gasser, M.I. Aly, Separation and recovery of rare earth elements from spent nickel-metal-hydride batteries using synthetic adsorbent. Int. J. Miner. Process. 121, 31-38 (2013)

29. European Parliament, Council of the European Union, Directive 2006/66/EC of the European Parliament and of the Council of 6 September 2006 on batteries and accumulators and waste batteries and accumulators and repealing Directive 91/157/EEC. Official Journal of European Union, L 266, pp. 1-14 (2006)

30. S. Al-Thyabat, T. Nakamura, E. Shibata, A. Iizuka, Adaptation of minerals processing operations for lithium-ion batteries (LiBs) and nickel metal hydride (NiMH) batteries recycling: critical review. Miner. Eng. 45, 4-17 (2013)

31. T. Muller, B. Friedrich, Development of a recycling process for nickel-metal hydride batteries. J. Power Sources 158, 1498-1509 (2006)

32. T. Georgi-Maschler, B. Friedrich, R. Weyhe, H. Heegn, M. Rutz, Development of a recycling processes for Li-ion batteries. J. Power Sources 207, 173-182 (2012)

33. P. Meshram, H. Somani, B.D. Pandey, T.R. Mankhand, H. Deveci, Abhilash, two stage leaching process for selective metal extraction from spent nickel metal hydride batteries. J. Clean. Prod. 157, 322-332 (2017)

34. K. Larsson, C. Ekberg, A. Ødegaard-Jehsen, Using Cyanex 923 for selective extraction in a high concentration chloride medium on nickel metal hydride battery waste, Part II: mixer-settler experiments. Hydrometallurgy 133, 168-175 (2013)

35. G. Xi, H. Xu, L. Yao, Study on preparation of NiCo ferrite using spent lithium-ion and nickel-metal hydride batteries. Sep. Purif. Technol. 145, 50-55 (2015)

36. M. Petranikova, I. Herdzik-Koniecko, B.-M. Steenari, C. Ekberg, Hydrometallurgical processes for recovery of valuable and critical metals from spent car NiMH batteries optimized in a pilot plant scale. Hydrometallurgy 171, 128-141 (2017)

37. A. Weibel, R. Bouchet, F. Boulc', P. Knauth, The big problem of small particles: a comparison of methods for determination of particle size in nanocrystalline anatase powders. Chem. Mater. 17, 2378-2385 (2005)

38. J. Lee, F. Zhou, K.H. Chung, N.J. Kim, E.J. Lavernia, Grain growth of nanocrystalline $\mathrm{Ni}$ powders prepared by cryomilling. Metall. Mater. Trans. A 32, 3109-3115 (2001) 